\title{
A Systematic Review of Mobile Health in Education From 2000 to 2016
}

Hakan Altinpulluk, Department of Distance Education, Anadolu University, Eskisehir, Turkey

\begin{abstract}
This article aims to examine the mobile health (mHealth) in education articles in journals covered by the SSCI and SCI-EXPANDED indices between 2000-2016. Five hundred and ninety-four (594) articles have been analyzed with a systematic review method. The change of the articles by year, the distribution according to the countries, universities, authors, citation analysis, and research fields were examined. As a result of this research, it was determined that the articles and citations have tended to increase rapidly after 2012. The US plays a pioneering role in this field, the universities in the USA publish most of the articles on the subject, and the USA-based authors dominate the field. In addition, it has been determined that mHealth-related articles tend to increase in undeveloped and developing countries, where mHealth projects are concentrated. Finally, based on research findings, some suggestions were made for researchers, developers and practitioners.
\end{abstract}

\section{KEYWORDS}

Database, Education, Health Systems, Healthcare, Index, mHealth, Mobile Health, Mobile Technology, Systematic Review, Trends 


\section{INTRODUCTION}

The first emergence of the mobile devices and later its adaptation by and proliferation in the society took only a short period. For instance, cellular mobile phone technology is regarded as one of the fastest adopted technologies in the history of humanity (Brian \& Ben-Zeev, 2014). Being independent of time and space, these ubiquitous technologies allow individuals to access information, to communicate with others, to collaborate, to play games and to get connected to social networks (Altinpulluk \& Kurubacak, 2016). Nowadays, as especially the smartphones and tablets are equipped with cameras, GPS, digital compass and various hardware and sensors, these mobile devices have been started to be used for different purposes than the communication purposes.

Mobile technologies are used in a variety of fields and sectors, from education to business, from banking to tourism. The health field is only one of these areas. The intensity of usage of smartphones and tablets can be seen strikingly in various reports. The number of smartphone users is forecasted to grow from 2.1 billion in 2016 to around 2.5 billion in 2019 , with smartphone penetration rates increasing as well. Just over 36 percent of the world's population is projected to use a smartphone by 2018, up from about 10 percent in 2011 (Statista, 2017). According to a report of We Are Social (2017) "Digital in 2017 Global Overview", 3,448 billion of the 3.773 billion active internet users are active mobile internet users at the same time. In the same report, the distribution of web traffics by the devices shows that mobile phones, 50\%, and tablets constitute the 5\% of the current web traffic. Reports in recent years show that smartphones and tablets will be even stronger and increasingly used in different areas.

Mobile devices are also used in various forms in the health field. Within this context, a concept called mobile health (mHealth) has emerged. Various definitions of mHealth have also been made. mHealth is broadly defined as the use of mobile devices as a vehicle to provide public health or medical interventions (Arora, Peters, Burner, Lam, \& Menchine, 2014). Mobile health is a newer concept that describes services supported by mobile communication devices, such as wireless patient monitoring devices, smartphones, personal digital assistants, and tablet computers (Weinstein et al., 2014). mHealth aims to capitalise on the rapid uptake of information and communication technologies (ICT) to improve health system efficiency and health outcomes (Agarwal et al., 2016). mHealth, a new paradigm of an emerging ICT artifact, transforms healthcare delivery around the world by making it more accessible, affordable and available (Akter, D'Ambra, \& Ray, 2013). mHealth applications can be used for a wide variety of purposes such as smoking cessation, weight loss, diet and physical activity, treatment adherence, and disease management (Fiordelli, Diviani, \& Schulz, 2013).

The rapid spread of mHealth projects has created great enthusiasm among governments, and healthcare practitioners (Labrique, Vasudevan, Chang, \& Mehl, 2013). With the increasing adoption of smart mobile devices and the continued development of mHealth applications and projects, the mHealth market is on the 
rise (Leijdekkers \& Gay, 2013; Miller, Cafazzo, \& Seto, 2016). Many reports have been prepared, which includes the utilization tendency of the mHealth that means the effective and efficient delivery of the healthcare services to the people by using the mobile devices.

According to a study conducted in 2013, in the past five years, mHealth applications were downloaded to $50 \%$ of 3.4 billion smartphones and tablets that had access to mobile applications (Research2guidance, 2013). By the end of 2017, total mHealth revenues are expected to reach $\$ 26$ billion (Research2guidance, 2014). These trend reports show that mHealth initiatives will increase day by day and invest more.

In this study, the use of mHealth in education, especially in medical and patient education, is examined. This study aims at reviewing and analyzing the articles about mHealth related education. In this context, a systematic review study is being conducted. A total of 594 articles were analyzed using the "Clarivate Analytics Web of Science Core Collection" database. In the literature, the absence of any study involving the subject of this article shows the importance and authenticity of study.

\section{BACKGROUND}

\section{Educational Use of mHealth Applications}

mHealth applications can be used in institutions for clinical, research, and educational purposes (Gaglani \& Topol, 2014). mHealth can be used in different ways under the education field. One of these uses is patient education.

Recent studies show that mobile devices and apps can support patient education (Franko \& Tirrel, 2012; Patel, Chapman, Luo, Woodruff, \& Arora, 2012). Mobile apps provide an excellent way to educate patients about the treatment process prior to enrolment (Price et al., 2014). Another form of education that is carried out effectively with mHealth is general health education. Innovations in information and communication technologies not only enriched health services but also made general health education an effective facilitator in reaching many people (Kamel Boulos \& Wheeler, 2007). There are also educational mHealth applications that aim to provide health education in many areas (Davis \& Oakley-Girvan, 2015).

In low-income countries, especially in health education, mHealth applications can be used as a cost-effective application. In countries with human and technology resource problems, mHealth applications have great potential to reach medical information (Littman-Quinn, Mibenge, Antwi, Chandra, \& Kovarik, 2013).

mHealth applications can also be used in medical education. There are many mHealth applications to increase the knowledge level of the students in Medical Faculties. The mHealth applications presented to medical students such as iMedEd are being frequently used (Gaglani \& Topol, 2014).

Apart from these areas, mHealth applications are also being developed and used in fields such as nursing education (Doran, 2009; Doswell, Braxter, Dabbs, Nilsen, \& Klem, 2013; McBride, 2012) and pharmacy education (Aungst, 2014). 
mHealth applications can provide educational support and information with "unique, timely, cost-effective" features in distance education programs (Bollinger, McKenzie-White, \& Gupta, 2011). In addition, it is mentioned in the literature that mHealth applications can be used in innovative educational technology trends such as "flipped classroom" (Gaglani \& Topol, 2014). In a flipped, or inverted, classroom: the teacher "delivers" lectures before class in the form of pre-recorded videos, and spends class time engaging students in learning activities that involve collaboration and interaction (Mok, 2014). It approaches to remove the traditional transmissive lecture and replace it with active in-class tasks and pre-/post-class work (Abeysekera \& Dawson, 2015).

\section{Systematic Review Studies in the Related Literature}

Although there have been no studies involving the analysis of education-related mHealth articles by systematic review, a wide range of systematic review studies of mHealth have been conducted.

In a systematic literature review by Zapata, Fernández-Alemán, Idri, \& Toval (2015), 22 studies on mHealth applications were selected, and the usability of mHealth applications was evaluated.

Aranda-Jan, Mohutsiwa-Dibe, \& Loukanova (2014) conducted a systematic review study on mHealth projects in Africa, using PubMed and OvidSP, between 2003 and 2013. Results were grouped to assess specific aspects of project implementation in terms of sustainability and mid/long-term results, integration to the health system, management process, scale up and replication, and legal issues, regulations and standards.

Mosa, Yoo, \& Sheets (2012) selected 2894 articles using MEDLINE and examined 83 smartphone applications discussed in 55 articles by systematic review. According to the results, the disease diagnosis, drug reference, and medical calculator applications were reported as most useful by healthcare professionals and medical or nursing students.

Agarwal, Perry, Long, \& Labrique (2015) have conducted a systematic review of mHealth articles published between 2000 and 2013 using five databases, MEDLINE, EMBASE, Global Health, Google Scholar and Scopus. This study aimed to review and synthesise the evidence on the feasibility and effectiveness of mobile-based services for healthcare delivery.

Similar to other authors, de la Torre-Díez, López-Coronado, Vaca, Aguado, \& de Castro (2015) used the academic databases "PubMed, Scopus, ISI Web of Science, and IEEE Xplore" in their systematic review study. In this study, 35 articles were examined. These articles are concerned with cost-utility and cost-effectiveness in Telemedicine, eHealth and mHealth systems. Authors have found that there are few studies about the cost-effectiveness in eHealth and mHealth, and some studies on the "cost-effectiveness" have reduced the costs in the field of telemedicine.

As can be understood from the reviewing in this section, there are many systematic review studies in the literature. However, it can be stated that these articles that are accessed are very different from the systematic review made within the scope of this 
study. In this study, mainly education-focused mHealth articles were examined in various dimensions, and the Web of Science database was used. Details of the study performed are specified in the following sections.

\section{METHODOLOGY}

\section{Systematic Review}

In this study, 594 articles about the educational use of mHealth in the "Web of Science" database were examined by systematic review. A systematic review is a means of evaluating and interpreting all available research relevant to a particular research question or topic area or phenomenon of interest (Kitchenham, 2004). In this context, systematic review studies aim to describe the existing literature, to critically review the evidence about the effectiveness of the obtained strategies and to detect the gaps in the knowledge base (Agarwal et al., 2015).

\section{Inclusion and Exclusion Criteria}

In this systematic review study, some criteria were identified, and only those articles that matched those criteria were analyzed.

The Web of Science database was selected, however the Biological Abstracts, the KCI-Korean Journal Database, the Russian Science Citation Index, and the SciELO Citation Index database are excluded. Biological Abstracts, the KCI-Korean Journal Database, the Russian Science Citation Index, and the SciELO Citation Index databases have "local" and limited features. The Web of Science Core Collection has been selected for its coverage of the most respected "international" journals.

"OR" is used in the search section because some article titles have "mobile health" and others have abbreviated "mHealth". In addition, for all of these articles to be relevant to education, "education" is written with the conjunction "AND". In the Timespan section, only publications between 2000 and 2016 were listed. Thus, previous publications from 2000 were not included in this study.

Finally, the criteria for the indexes have been determined. In this section, SCIEXPANDED, which is the most important index in the field of science, of which the database is active from 1980 to the present day, and SSCI, which is the most esteemed index in social sciences launched in 1980, were selected. These two indices have been chosen because the mHealth articles on education can be found in both "Science" and "Social Science". In this context, the selection of indices of "Arts \& Humanities Citation Index (A\&HCI), Conference Proceedings Citation Index-Science (CPCI-S), Conference Proceedings Citation Index- Social Science \& Humanities (CPCI- SSH), Emerging Sources Citation Index (ESCI) was not considered necessary.

These criteria have been deemed appropriate for the selection of the most important articles on this subject. In this phase, 1017 documents were listed in the database. 423 documents were excluded from the analysis. The type of these publications is "meeting abstract (203), review (87), editorial material (81), letter (27), news item (15), proceedings paper (14), correction (6), book review (3), book chapter (3), and 
retraction (1)". At this point, since only the articles were planned to be filtered, 594 articles were listed by selecting the "article" option on the left and then analyzed. Thus, a search code like the one below is generated.

TITLE: (mobile health) OR TITLE: (mHealth) AND TOPIC: (education) Refined by: DOCUMENT TYPES: (ARTICLE) Timespan: 2000-2016. Indexes: SCI-EXPANDED, SSCI.

The results obtained in this study are limited to the Web of Science Core Collection database only.

\section{RESULTS}

Within the scope of this study, 594 articles were analyzed and graphics were visualized by using the tool "Datamatic (http://datamatic.io)". Thus, thanks to visuals, data analysis has become easier to understand. Additional visualizations were made in the graphics and maps created with Datamatic and Adobe Photoshop CS5.

As a result of the systematic review, some findings were obtained. In this context, as a result of the research, the distribution of the mHealth articles related to education was determined by country, university, author, citation and research field. These findings are presented in the following subheadings.

\section{Changes in Number of Article Published by Years}

The distribution chart of the articles covering mHealth apps for education is shown in Figure 1. According to this finding, from 2000's to 2010, the number of articles seems to be low. For instance, in 2000, only three articles were published on this subject. There were no significant jumps on the chart until 2000. The high trend, which started with 55 articles especially after 2012, reached maximum number $(n=143)$ in 2016.

\section{Major Contributing Countries}

The maps and graphics under this heading have been made with Datamatic and enriched with Adobe Photoshop (Figure 2). According to the map, the U.S. by far takes place on the top with 292 articles. England, as the closest to that number, takes the second place with 50 articles. In the map, only the U.S. has more than 50 articles, and it is shown in red color. As it is seen on the map, categorization is indicated with the colors. The highest numbers are shown in red, and the lowest numbers are shown in yellow.

The countries that have less than five articles are indicated in black font. According to the map, all the continents have articles written on this subject, especially the articles written in the African continent, notably South Africa ( $\mathrm{n}=16)$, Kenya $(\mathrm{n}=$ $10)$, Uganda $(n=8)$, Ghana $(n=6)$ were colored on the map. There are also countries except those that are not indicated with colors because of the reason that they have less than five articles, such as Ethiopia $(n=4)$, Nigeria $(n=4)$, Tanzania $(n=4)$, Zambia $(n=4)$, and Morocco $(n=3)$. When the map is examined, it can be seen that the number of publications in European and North American countries is increasing.

The graphic shown in Figure 3 was also created with Datamatic and enriched with Adobe Photoshop. In this chart, the top 5 countries with the highest number of articles are examined. Especially when the circles of the US are examined, the considerable increase 
in the number of articles in the last five years can be seen. There has also been an upward trend in the number of articles in the last five years in England, Australia, Canada and China. Circular sizes related to article numbers are visualized based on real numbers.

\section{Major Contributing Universities}

As the universities that have completed the most articles are examined, the University of California, LA (UCLA) takes the first place with 18 articles (Figure 4). Harvard University and University of California, SF $(n=16)$ draw attention as the other leading universities in this field. As shown in the chart, it can be seen that the first seven universities are all US-based.

Some of the universities that are not included in this chart and which are different from the U.S. are as follows:

- The University of Sydney (Australia) $(\mathrm{n}=10)$

- University of Oxford (England) $(\mathrm{n}=8)$

- McMaster University (Canada) $(\mathrm{n}=7)$

\section{The Authors Who Prepared the Most Articles}

According to the distribution by authors (Figure 5), Piette JD compels attention as the author who completed the most articles on this field with nine articles, and Schuz J. is the second with six articles. Bakken, Atienza, Dabbs, and Snow are the other authors who published the most articles on this subject.

\section{Citation Analysis}

The change in citation counts by years was determined by citation analysis. This graph is shown in detail in Figure 6. As the graphic prepared with "Datamatic" shows, the number of citations increases every year without exception. In addition, this increase exponentially continues year by year, and the graphic shows that more articles have been cited especially after 2014. As can be seen from the graph, in 2016, the number of citations reached the highest point.

Figure 7 also shows the list of most cited articles between 2000-2016 among 594 articles. The most cited article is "Mobile Phone Based Clinical Microscopy for Global Health Applications" with 266 citations.

\section{Research Fields}

When the analyzed articles are examined by research fields (Figure 8), it is seen that most of the mHealth published articles on education are in the field of Health Care Sciences \& Services research. Looking at Figure 8, it is understood that educational mHealth articles have also been published in the Medical Informatics and Public Environmental \& Occupational Health research fields. Computer Science and Engineering are also listed, indicating that this area is also in integration with fields requiring technical knowledge besides medicine and education fields. Other research fields are General Internal Medicine, Telecommunications and Nursing. 
International Journal of Reliable and Quality E-Healthcare

Volume 7 • Issue 3 • July-September 2018

Figure 1. Changes in number of articles published by years

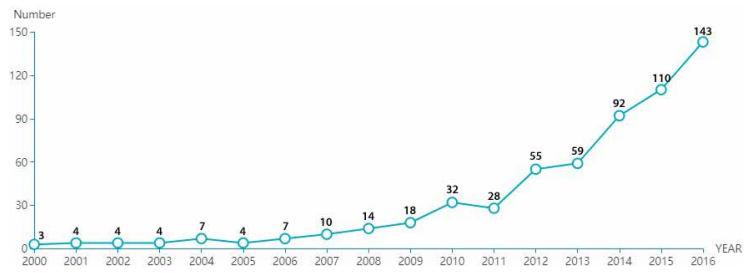

Figure 2. Major contributing countries

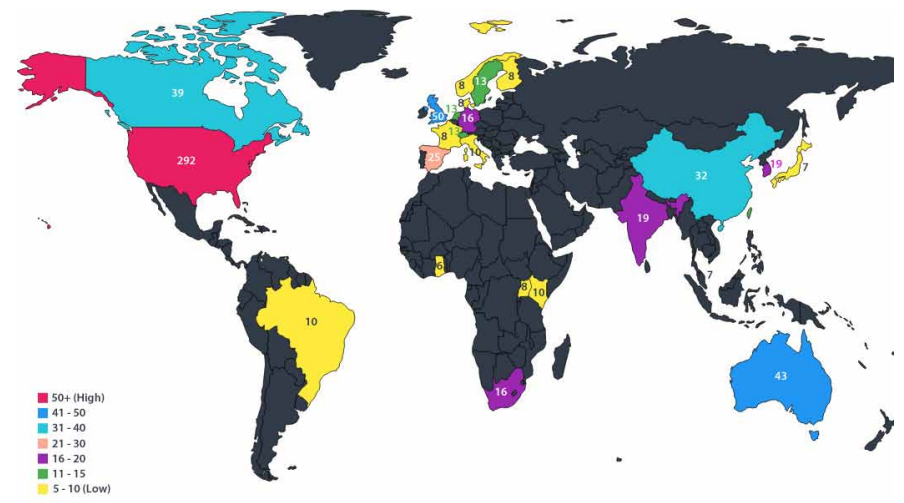

Figure 3. Five countries where most articles are published

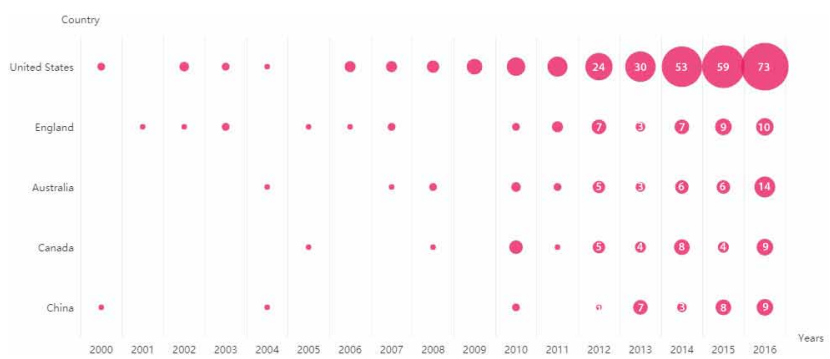

Figure 4. Number of articles and universities

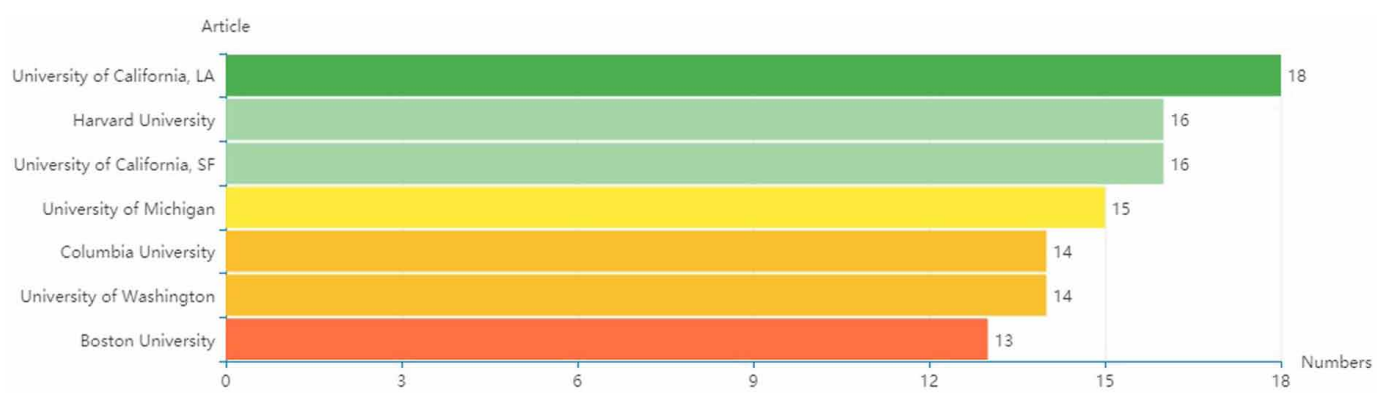


Figure 5. The authors who prepared the most articles

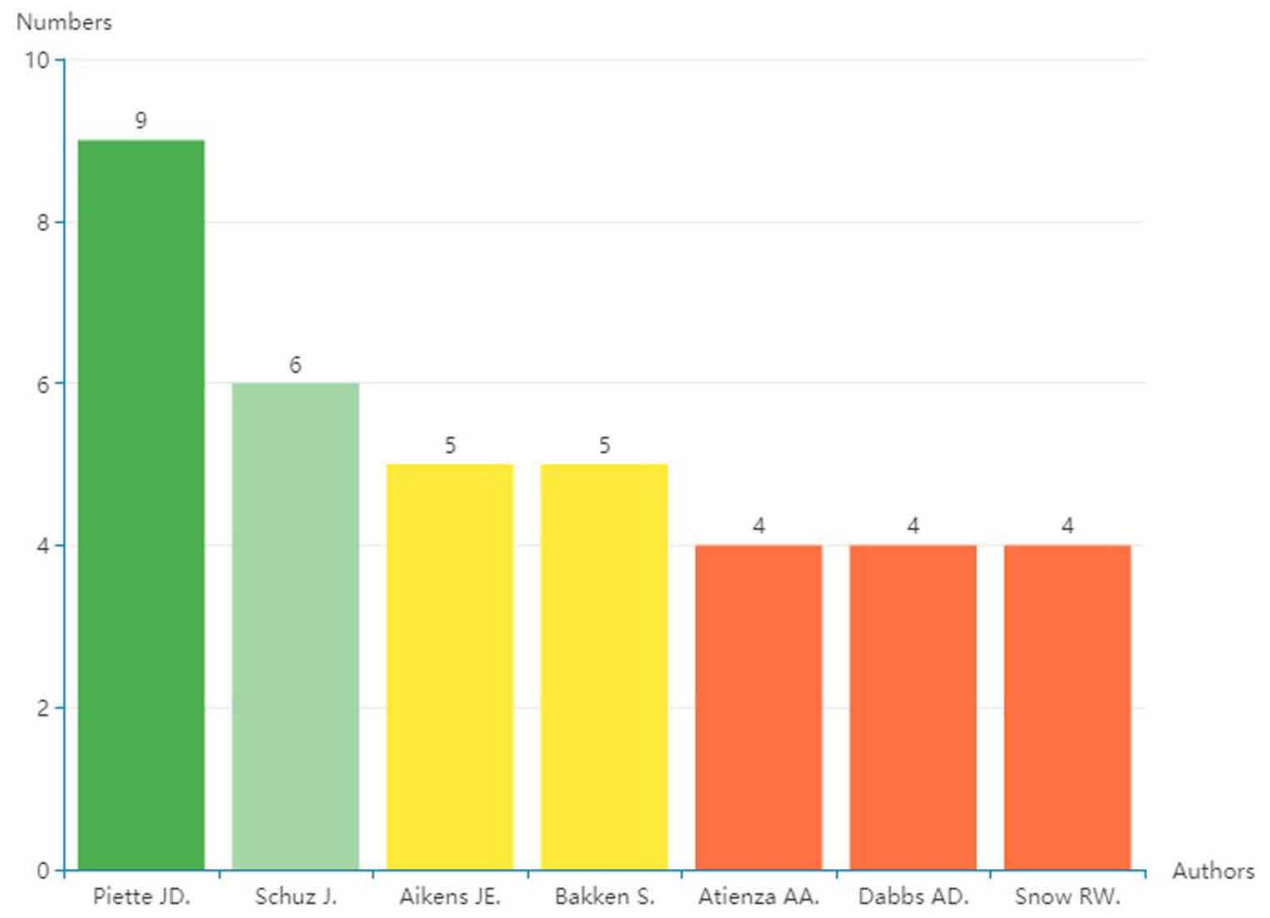

Figure 6 . The change in the number of citations by year

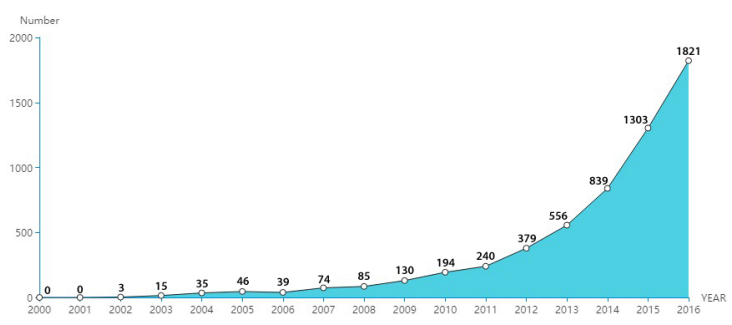

\section{DISCUSSION}

In this study, a systematic review of 594 mHealth articles related to education was conducted between 2000-2016. In the analysis of the articles in the journals that are reviewed in the SSCI and SCI-EXPANDED indexes found in the Web of Science database, visualizations were made using various tools, and some results were obtained.

According to the results of this study, there are not many articles published about the mHealth studies and education in the 2000's. There have not been many articles published during the ten years after the 2000's. That proves that mHealth has become popular after 2010 and shows a trend at increasingly high pace. Also, this reveals that the articles on this subject are relatively new. The increasing number of publications 


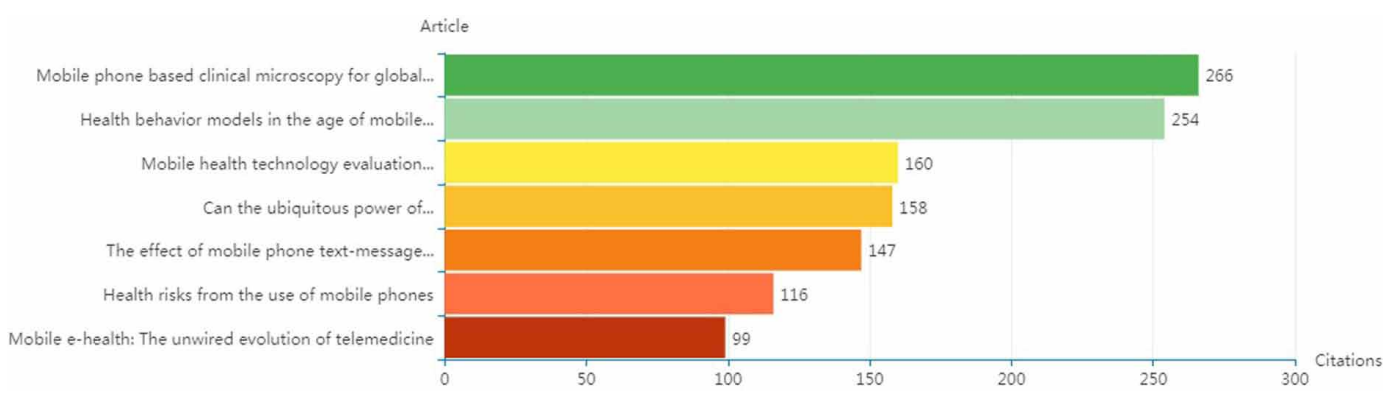

Figure 8. Research fields

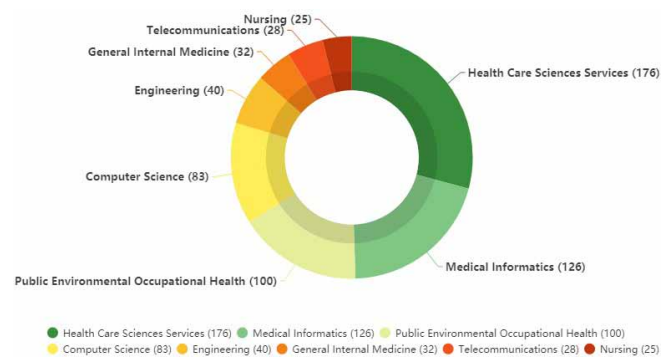

about mHealth indicates that the use of mobile devices in the healthcare field will increase in the future.

Among the countries that have publications in the field, the U.S. comes by far the first and England is in the second place. Although academic publications are usual in countries with high levels of education and income, it is an exciting finding of this systematic study that the undeveloped and developing countries also have many articles on the subject. Relevant literature (Alghamdi, Gashgari, \& Househ, 2015; Beratarrechea et al., 2014; Busse, Aboneh, \& Tefera, 2014; Chib, van Velthoven, \& Car, 2015; World Health Organization, 2011) reveals that recently, mHealth applications have often been used in undeveloped and developing countries. In this context, the finding of this study supports and proves this situation. It is noteworthy finding that particularly the publications in the African continent is on the rise.

There are vast differences between developed countries, and low income and undeveloped in terms of the access to health services (Vishwanath et al. 2012). mHealth is a necessity especially for such countries in the African continent with the opportunities it offers and has a great potential (WHO, 2011). The results of this study prove the day by day increase in the number of academic studies and articles in these low-income countries.

US-based universities are listed among the universities where the most articles are completed. Relevant literature also confirms that the U.S. based universities play a leading role in terms of mHealth projects (Ybarra, Holtrop, Prescott, \& Strong, 2014). In this study, USA has been already determined as the country where the most articles 
were published. At this point, it was an expected result that mostly the universities in the U.S. would play a leading role in this field. It was determined that the U.S. based authors appear in the top rankings with respect to highest numbers of publication. This fact reaffirms that the U.S. is the country that dominates and leads this field.

It has been observed that the number of citations increased year by year in a stable manner. This finding is parallel to the graph of the increase in the number of publications and confirms each other. The high acceleration in both graphs especially after the 2010's proves that the numbers of publications and citations affect each other with a direct proportion and positive correlation.

It can be considered as a natural fact to find Healthcare Sciences \& Services come first when examining mHealth articles for educational purposes sorted by research areas. Looking at other areas relevant to mHealth, the close relationship between technology and mHealth is striking. The inclusion of related areas such as Medical Informatics, Computer Science, Engineering and Telecommunications in this list is evidence of the relevance of the mHealth concept to technology and technical sciences. It can be stated that mHealth applications which have the aim of enriching and facilitating health services with telecommunication technologies (Dwivedi, Shareef, Simintiras, Lal, \& Weerakkody, 2016) are also closely related to the engineering field besides medicine and education field.

\section{CONCLUSION}

With the results obtained from this study, various suggestions can be offered to the mobile application developers, academicians, educators, and practitioners.

Even though mHealth is a concept that has an excellent potential for a more effective and efficient delivery of health services to the people in low-income countries, the U.S. is the leading figure in this field (in terms of the number of authors, universities, publications, and citations). In recent years, even though the projects and articles tend to increase in undeveloped and developing countries, we can say that further research is required. It is suggested that these countries should make use of the opportunities that mHealth offers. In addition, it can also be recommended that the mHealth applications' developers should further concentrate on developing health education-based mobile application.

The use of mHealth applications for education purposes is only one of its uses. It was determined that there be a need for further academic research on the subject. Another result obtained from this study is the incremental increase in the number of the studies in this field in the last years. It is of high importance that this trend continues in the next years. Additionally, as different from this study, it is suggested to contribute to the literature by conducting a systematic review, bibliometric analysis, meta-analysis or content analysis through various variables related to mHealth ranging by year, indices, type of database to the keywords. In addition, the scope of the analysis can be expanded by adding different dimensions. In this context, researchers may contribute to the scientific literature by examining various variables such as which 
languages the mHealth articles are written in, which mobile applications or operating systems are heavily used, which subdisciplines are associated, which scientific research method is employed, which mobile devices are used and which sample group is preferred. Within the scope of this study, it has emerged that the fields of medicine, education and engineering are leading mHealth researches. New research enriched by the combination of the forces of these three disciplines is thought to be an element that will help mHealth practices to shape in the future. 


\section{REFERENCES}

Abeysekera, L., \& Dawson, P. (2015). Motivation and cognitive load in the flipped classroom: Definition, rationale and a call for research. Higher Education Research \& Development, 34(1), 1-14. doi:10.1080/07294360.2014.934336

Agarwal, S., LeFevre, A. E., Lee, J., L'Engle, K., Mehl, G., Sinha, C., \& Labrique, A. (2016). Guidelines for reporting of health interventions using mobile phones: Mobile health (mHealth) evidence reporting and assessment (mERA) checklist. British Medical Journal, 352. doi:10.1136/bmj.i1174 PMID:26988021

Agarwal, S., Perry, H. B., Long, L. A., \& Labrique, A. B. (2015). Evidence on feasibility and effective use of mHealth strategies by frontline health workers in developing countries: Systematic review. Tropical Medicine \& International Health, 20(8), 1003-1014. doi:10.1111/tmi.12525 PMID:25881735

Akter, S., D’Ambra, J., \& Ray, P. (2013). Development and validation of an instrument to measure user perceived service quality of mHealth. Information \& Management, 50(4), 181-195. doi:10.1016/j.im.2013.03.001

Alghamdi, M., Gashgari, H., \& Househ, M. (2015). A systematic review of mobile health technology use in developing countries. Studies in Health Technology and Informatics, 213, 223-226. PMID:26152999

Altinpulluk, H., \& Kurubacak, G. (2016). MoBip Project: To Raise Awareness about Bipolar Disorder through an 3D Pop-Up Book. In A. Moumtzoglou (Ed.), M-Health Innovations for Patient-Centered Care (pp. 147-169). Hershey, PA: IGI Global. doi:10.4018/978-1-4666-9861-1.ch008

Aranda-Jan, C. B., Mohutsiwa-Dibe, N., \& Loukanova, S. (2014). Systematic review on what works, what does not work and why of implementation of mobile health (mHealth) projects in Africa. BMC Public Health, 14(1), 188. doi:10.1186/14712458-14-188 PMID:24555733

Arora, S., Peters, A. L., Burner, E., Lam, C. N., \& Menchine, M. (2014). Trial to examine text message-based mHealth in emergency department patients with diabetes (TExT-MED): A randomized controlled trial. Annals of Emergency Medicine, 63(6), 745-754. doi:10.1016/j.annemergmed.2013.10.012 PMID:24225332

Aungst, T. D. (2014). Integrating mHealth and mobile technology education into the pharmacy curriculum. American Journal of Pharmaceutical Education, 78(1), 19. doi:10.5688/ajpe78119 PMID:24558287

Beratarrechea, A., Lee, A. G., Willner, J. M., Jahangir, E., Ciapponi, A., \& Rubinstein, A. (2014). The impact of mobile health interventions on chronic disease outcomes in developing countries: A systematic review. Telemedicine Journal and e-Health, 20(1), 75-82. doi:10.1089/tmj.2012.0328 PMID:24205809 
Bollinger, R. C., McKenzie-White, J., \& Gupta, A. (2011). Building a global health education network for clinical care and research. The benefits and challenges of distance learning tools. Lessons learned from the Hopkins Center for Clinical Global Health Education. Infectious Disease Clinics of North America, 25(2), 385-398. doi:10.1016/j.idc.2011.02.006 PMID:21628053

Brian, R. M., \& Ben-Zeev, D. (2014). Mobile health (mHealth) for mental health in Asia: Objectives, strategies, and limitations. Asian Journal of Psychiatry, 10, 96-100. doi:10.1016/j.ajp.2014.04.006 PMID:25042960

Busse, H., Aboneh, E. A., \& Tefera, G. (2014). Learning from developing countries in strengthening health systems: An evaluation of personal and professional impact among global health volunteers at Addis Ababa University's Tikur Anbessa Specialized Hospital (Ethiopia). Globalization and Health, 10(1), 64. doi:10.1186/s12992-0140064-x PMID:25190076

Chib, A., van Velthoven, M. H., \& Car, J. (2015). mHealth adoption in low-resource environments: A review of the use of mobile healthcare in developing countries. Journal of Health Communication, 20(1), 4-34. doi:10.1080/10810730.2013.864735 PMID:24673171

Davis, S. W., \& Oakley-Girvan, I. (2015). mHealth education applications along the cancer continuum. Journal of Cancer Education, 30(2), 388-394. doi:10.1007/ s13187-014-0761-4 PMID:25482319

de la Torre-Díez, I., López-Coronado, M., Vaca, C., Aguado, J. S., \& de Castro, C. (2015). Cost-utility and cost-effectiveness studies of telemedicine, electronic, and mobile health systems in the literature: A systematic review. Telemedicine Journal and e-Health, 21(2), 81-85. doi:10.1089/tmj.2014.0053 PMID:25474190

Doran, D. (2009). The emerging role of PDAs in information use and clinical decision making. Evidence-Based Nursing, 12(2), 35-38. doi:10.1136/ebn.12.2.35 PMID:19321815

Doswell, W. M., Braxter, B., Dabbs, A. D., Nilsen, W., \& Klem, M. L. (2013). mHealth: Technology for nursing practice, education, and research. Journal of Nursing Education and Practice, 3(10), 99. doi:10.5430/jnep.v3n10p99

Dwivedi, Y. K., Shareef, M. A., Simintiras, A. C., Lal, B., \& Weerakkody, V. (2016). A generalised adoption model for services: A cross-country comparison of mobile health (m-health). Government Information Quarterly, 33(1), 174-187. doi:10.1016/j. giq.2015.06.003

Fiordelli, M., Diviani, N., \& Schulz, P. J. (2013). Mapping mHealth research: A decade of evolution. Journal of Medical Internet Research, 15(5), e95. doi:10.2196/ jmir.2430 PMID:23697600

Franko, O. I., \& Tirrell, T. F. (2012). Smartphone app use among medical providers in ACGME training programs. Journal of Medical Systems, 36(5), 3135-3139. doi:10.1007/s10916-011-9798-7 PMID:22052129 
Gaglani, M. S. M., \& Topol, E. J. (2014). iMedEd: The role of mobile health technologies in medical education. Academic Medicine: Journal of the Association of American Medical Colleges, 89(9), 1207-1209. doi:10.1097/ACM.0000000000000361 PMID:24892404

Kamel Boulos, M. N., \& Wheeler, S. (2007). The emerging Web 2.0 social software: An enabling suite of sociable technologies in health and health care education. Health Information and Libraries Journal, 24(1), 2-23. doi:10.1111/j.14711842.2007.00701.x PMID:17331140

Kitchenham, B. (2004). Procedures for performing systematic reviews. Keele, UK, Keele University, 33(2004), 1-26.

Kumar, S., Nilsen, W. J., Abernethy, A., Atienza, A., Patrick, K., Pavel, M., \& Hedeker, D. et al. (2013). Mobile health technology evaluation: The mHealth evidence workshop. American Journal of Preventive Medicine, 45(2), 228-236. doi:10.1016/j. amepre.2013.03.017 PMID:23867031

Labrique, A., Vasudevan, L., Chang, L. W., \& Mehl, G. (2013). H_pe for mHealth: More "y" or "o" on the horizon? International Journal of Medical Informatics, 82(5), 467-469. doi:10.1016/j.ijmedinf.2012.11.016 PMID:23279850

Leijdekkers, P., \& Gay, V. (2013). Mobile apps for chronic disease management: Lessons learned from myFitnessCompanion ${ }^{\circledR}$. Health and Technology, 3(2), 111-118. doi:10.1007/s 12553-013-0044-9

Littman-Quinn, R., Mibenge, C., Antwi, C., Chandra, A., \& Kovarik, C. L. (2013). Implementation of m-health applications in Botswana: Telemedicine and education on mobile devices in a low resource setting. Journal of Telemedicine and Telecare, 19(2), 120-125. doi:10.1177/1357633x12474746 PMID:23454821

McBride, D. L. (2012). The distracted nurse. Journal of Pediatric Nursing, 27(3), 275-276. doi:10.1016/j.pedn.2012.02.002 PMID:22391149

Miller, A. S., Cafazzo, J. A., \& Seto, E. (2016). A game plan: Gamification design principles in mHealth applications for chronic disease management. Health Informatics Journal, 22(2), 184-193. doi:10.1177/1460458214537511 PMID:24986104

Mok, H. N. (2014). Teaching tip: The flipped classroom. Journal of Information Systems Education, 25(1), 7-11.

Mosa, A. S. M., Yoo, I., \& Sheets, L. (2012). A systematic review of healthcare applications for smartphones. BMC Medical Informatics and Decision Making, 12(1), 67. doi:10.1186/1472-6947-12-67 PMID:22781312

Patel, B. K., Chapman, C. G., Luo, N., Woodruff, J. N., \& Arora, V. M. (2012). Impact of mobile tablet computers on internal medicine resident efficiency. Archives of Internal Medicine, 172(5), 436-438. doi:10.1001/archinternmed.2012.45 PMID:22412110 
Price, M., Yuen, E. K., Goetter, E. M., Herbert, J. D., Forman, E. M., Acierno, R., \& Ruggiero, K. J. (2014). mHealth: A mechanism to deliver more accessible, more effective mental health care. Clinical Psychology \& Psychotherapy, 21(5), 427-436. doi:10.1002/cpp.1855 PMID:23918764

Research2Guidance. (2013). Mobile health market report 2013-2017. Retrieved from http://www.research2guidance.com/shop/index.php/downloadable/download/sample/ sample_id/262

Research2Guidance. (2014). mHealth app developer economics 2014. Retrieved from http://research2guidance.com/r2g/research2guidance-mHealth-App-DeveloperEconomics-2014.pdf

Statista. (2017). Number of smartphone users worldwide from 2014 to 2020 (in billions). Retrieved from https://www.statista.com/statistics/330695/number-ofsmartphone-users-worldwide/

Vishwanath, S., Vaidya, K., Nawal, R., Kumar, A., Parthasarathy, S., \& Verma, S. (2012). Touching lives through mobile health. Retrieved from https://www.pwc. in/en_IN/in/assets/pdfs/publications-2012/touching-lives-through-mobile-healthfebruary-2012.pdf

Vithanwattana, N., Mapp, G., \& George, C. (2016). mHealth-Investigating an information security framework for mHealth data: Challenges and possible solutions. In Proceedings of the 2016 12 th International Conference on Intelligent Environments (IE) (pp. 258-261). IEEE.

We Are Social. (2017). Digital in 2017 global overview. Retrieved from https://www. slideshare.net/wearesocialsg/digital-in-2017-global-overview

Weinstein, R. S., Lopez, A. M., Joseph, B. A., Erps, K. A., Holcomb, M., Barker, G. P., \& Krupinski, E. A. (2014). Telemedicine, telehealth, and mobile health applications that work: Opportunities and barriers. The American Journal of Medicine, 127(3), 183-187. doi:10.1016/j.amjmed.2013.09.032 PMID:24384059

World Health Organization (WHO). (2011). mHealth: New horizons for health through mobile technologies. Retrieved from http:/www.who.int/goe/publications/ goe_mhealth_web.pdf

Ybarra, M. L., Holtrop, J. S., Prescott, T. L., \& Strong, D. (2014). Process evaluation of a mHealth program: Lessons learned from Stop My Smoking USA, a text messagingbased smoking cessation program for young adults. Patient Education and Counseling, 97(2), 239-243. doi:10.1016/j.pec.2014.07.009 PMID:25103183

Zapata, B. C., Fernández-Alemán, J. L., Idri, A., \& Toval, A. (2015). Empirical studies on usability of mHealth apps: A systematic literature review. Journal of Medical Systems, 39(2), 1. doi:10.1007/s10916-014-0182-2 PMID:25600193 
Hakan Altınpulluk is a Research Assistant in Distance Education at the College of Open Education of Anadolu University, Turkey. He undertook undergraduate studies in the field of Computer Education and Instructional Technologies (CEIT) between the years of 2005-2009 at Anadolu University. Also, he is currently a doctoral student in the Department of Distance Education at Anadolu University since 2010. Hakan Altınpulluk continues to work in the field of Open and Distance Education, Augmented Reality, Virtual Reality, Mobile Learning, Mobile Health, Massive Open Online Courses, Learning Management Systems, Open Educational Resources, Personal Learning Environments, and E-Learning Systems. 